\title{
A narrative review of nutritional abnormalities, complications, and optimization in the cirrhotic patient
}

\author{
Edgewood R. Warner II ${ }^{1}$, Fuad Z. Aloor, Sanjaya K. Satapathy ${ }^{2}$ \\ ${ }^{1}$ Department of Medicine, Donald and Barbara Zucker School of Medicine/Northwell Health, Manhasset, NY, USA; ${ }^{2}$ Division of Hepatology \\ and Sandra Atlas Bass Center for Liver Diseases and Transplantation, Department of Medicine, Donald and Barbara Zucker School of Medicine/ \\ Northwell Health, Manhasset, New York, USA \\ Contributions: (I) Conception and design: SK Satapathy; (II) Administrative support: SK Satapathy; (III) Provision of study materials or patients: All \\ authors; (IV) Collection and assembly of data: ER Warner 2nd; (V) Data analysis and interpretation: ER Warner 2nd; (VI) Manuscript writing: All \\ authors; (VII) Final approval of manuscript: All authors. \\ Correspondence to: Sanjaya K. Satapathy, MBBS, MD, DM, MS (Epi), FACG, FASGE, AGAF, FAASLD. Medical Director, Liver Transplantation, \\ Division of Hepatology at Sandra Atlas Bass Center for Liver Diseases \& Transplantation, Association Professor of Medicine, Donald and Barbara \\ Zucker School of Medicine/Northwell Health, 400 Community Drive, Manhasset, NY 11030, USA. Email: ssatapat@northwell.edu.
}

\begin{abstract}
Objective: The purpose of this manuscript is to identify the pathophysiology of the metabolic abnormalities observed in cirrhosis and to uncover associations, if any, to its complications, such as sarcopenia and hepatic encephalopathy (HE).

Background: Liver dysfunction in cirrhosis is known to be a precipitating factor in the disruption of many physiological pathways, specifically nutrient metabolism. As a result, affected patients are highly susceptible to derangements of processes affecting multiple classes of macro- and micronutrients, including proteins, carbohydrates, electrolytes, vitamins, and minerals. These disruptions are thought to be contributory to the pathogenesis of known complications of cirrhosis.

Methods: Literature research of relevant topics was conducted for the above stated objective; sources were limited to articles from peer-reviewed journals published within the last 30 years.

Conclusion: This research established that there is positive correlation between nutrient derangements and the increased risk of complications of cirrhosis, which themselves carry significant morbidity and mortality risk. It also established that some nutrient and electrolyte abnormalities are independent indicators of prognosis and adverse outcomes, such as mortality. This also highlights the importance of comprehension of anomalous metabolism and its complications as it necessitates serious consideration in clinical care. In addition to medical management, cirrhotic patients also require ancillary assessment, such as comprehensive nutritional evaluation, to identify and treat reversible nutritional derangements. This consideration provides the best opportunity to achieve maximal health outcomes in the cirrhotic patient population.
\end{abstract}

Keywords: Cirrhosis; liver; metabolism; nutrient; protein

Received: 27 October 2020; Accepted: 08 April 2021; Published: 25 January 2022.

doi: $10.21037 / \mathrm{tgh}-20-325$

View this article at: http://dx.doi.org/10.21037/tgh-20-325

\section{Introduction}

Liver dysfunction in cirrhosis predisposes patients to derangements of nutrient metabolism. These changes in the processing of macro- and micronutrients precipitate poor nutritional states that modify body composition, decrease functional capacity, and increase the likelihood of complications and poor health outcomes. The purpose of this article is threefold: (I) to highlight the nutritional deficiencies and the mechanisms by which they occur; (II) to discuss the potential adverse consequences of these deficiencies; and (III) to address the means by which to assess for and manage these 
deficiencies to maximize health outcomes in the cirrhotic patient. We present the following article in accordance with the Narrative Review reporting checklist (available at https:// tgh.amegroups.com/article/view/10.21037/tgh-20-325/rc).

\section{Protein deficiency}

The liver plays an essential role in protein metabolism, including synthesis of a majority of serum proteins and amino acid processing (1). Hepatic dysfunction as a result of cirrhosis facilitates a state of overall protein deficiency. Convergent pathways work in concert to create this deficiency. For one, cirrhotic patients often suffer from decreased oral intake. Factors such as early satiety due to ascites, fluctuations in ghrelin and leptin, salt-restricted and protein-restricted diets, and nausea and vomiting can contribute to diminished food consumption (2-5). This is of particular consequence to older patients, as it is known that oral intake decreases with increased age (2). In addition to reduced consumption of amino acid building blocks, cirrhotic patients lose the capacity to maintain proper homeostatic balance of protein metabolism. That is, the liver's protein synthetic function and amino acid modification is greatly impaired (2). Furthermore, disturbances of metabolism of other macronutrients, particularly fat malabsorption and glycogen storage abnormalities, insulin resistance, and increased adrenergic activity leads to increased gluconeogenesis powered by amino acids sourced increased breakdown and catabolism of protein $(5,6)$.

\section{Fluid imbalance}

Cirrhosis also causes irregularities in fluid balance; this results in ascites, or increased fluid within the abdominal cavity (7). Cirrhosis is the culmination of chronic liver pathology characterized by the presence of regenerative nodules and extensive fibrosis (8). This change in the liver architecture increases portal resistance and causes blood pooling within the portal system, leading to portal hypertension $(7,9)$. Compensatory mechanisms, particularly increased nitric oxide production, are activated, resulting in arteriolar and splanchnic vasodilation (7). Arteriolar vasodilation creates functional hypovolemia; this particularly impacts the kidney as it causes renal hypoperfusion, stimulating activation of the renin-angiotensin-aldosterone system (RAAS) and ensuing sodium and fluid retention $(7,10)$. Increased fluid, increased portal pressure, vascular dilation, decreased oncotic pressure due to loss of serum proteins like albumin, and limitation of lymphatic system compensation allows for increased fluid filtration from blood vessels and translocation into the abdomen $(7,10,11)$.

\section{Electrolyte abnormalities}

\section{Sodium}

One of the most common electrolyte abnormalities in cirrhosis is hyponatremia, or a sodium level below 130 (12). Hyponatremia is mediated by the activation of the RAAS and, in particular, the activity of antidiuretic hormone $(\mathrm{ADH})$ in the setting of renal hypoperfusion due to arteriolar dilation $(7,10)$. ADH promotes free water reabsorption which not only increases fluid volume, but also dilutes the concentration of serum electrolytes, specifically sodium, resulting in hypervolemic hyponatremia, the most common type of hyponatremia in the cirrhotic patient $(12,13)$. Hypovolemic hyponatremia, or low sodium levels in the setting of decreased fluid volume, can also occur, but it is less common and is typically attributed to excessive diuresis (13).

\section{Magnesium}

Magnesium is an essential cofactor in many metabolic processes, including mitochondrial function and protein synthesis (14). A cirrhotic patient may experience magnesium deficiency through reduced intake in the diet and reduced absorption in the intestine; circulating levels in the body may also be reduced due to the lower levels of albumin, an important cotransport protein $(14,15)$. Lastly, the kidneys are an important homeostatic regulator of magnesium as they are responsible for reabsorption of magnesium from filtrate; renal dysfunction (kidney injury or failure in hepatorenal syndrome), fluid shifts (ascites), and management (diuresis) in cirrhosis may cause insensible renal losses $(14,15)$.

\section{Potassium}

\section{Hypokalemia}

Multiple physiological mechanisms act to produce decreased potassium levels. The activation of RAAS, notably the increased adrenergic and aldosterone activity, are factors 
that can lower serum potassium concentration. Adrenergic tone, specifically $\beta$-adrenoreceptor stimulation, contributes by driving potassium intracellularly $(16,17)$. Increased aldosterone activity causes hypokalemia by stimulation of the epithelial sodium channels, which reabsorbs sodium and excretes potassium into urine $(16,18)$. Additionally, as with the other electrolytes, potassium may also become depleted as a result of diuresis (16).

\section{Hyperkalemia}

Cirrhosis, specifically advanced cases can precipitate hepatorenal syndrome; hepatorenal syndrome is defined by the International Ascites Club as the following: functional renal failure in the setting of liver disease with creatinine levels greater than $1.5 \mathrm{mg} / \mathrm{dL}$ (or $133 \mu \mathrm{mol} / \mathrm{L}$ ); absence of shock state, infection, drug toxicity, overt gastrointestinal or renal fluid loss, proteinuria in excess of $0.5 \mathrm{~g} / \mathrm{d}$, and imaging evidence of renal disease or distal obstruction; no improved renal function following $1.5 \mathrm{~L}$ of fluid resuscitation and discontinuation of diuretics (19). RAAS-mediated vasoconstriction of systemic circulation assists in the preservation of renal perfusion $(19,20)$. However, the renal vasculature also becomes vasoconstricted and, as cirrhosis progresses, the drastic reduction of renal blood flow and glomerular filtration rate (GFR) results in kidney injury and failure $(19,20)$. This presents the risk of hyperkalemia due to decreased delivery of sodium to distal tubule and decreased ability of the kidney to excrete potassium; potassium-sparing diuretics like spironolactone may also contribute to hyperkalemia $(16,21,22)$.

\section{Vitamin and micronutrient deficiencies}

\section{Fat-soluble vitamins (vitamins $A, D, E, K$ )}

All fat-soluble vitamins require the actions of bile acid salts for absorption (23). In cirrhosis, however, bile acid secretion into the intestinal lumen is diminished, causing ineffective absorption of vitamins A, D, E, and K $(24,25)$.

\section{Vitamin D}

Vitamin D is essential for the intestinal absorption of calcium and phosphate and the maintenance of bone $(26,27)$. The substrate vitamin D3 is acquired from diet or synthesized from 7-dehydrocholesterol in sun-exposed skin; it requires hepatic enzymatic conversion to 25 -hydroxyvitamin $\mathrm{D}$ before it is further hydroxylated to the active 1,25-dihydroxyvitamin $\mathrm{D}$ form in the kidney (26). Vitamin D is also largely transported throughout the body by hepatically-synthesized vitamin-D binding proteins (DBP) and albumin (27). In addition to malabsorption, vitamin $\mathrm{D}$ deficiency is acquired from other etiologies, including defective liver enzyme activity, reduced circulating transporter proteins, and generalized poor appetite (27).

\section{Water-soluble vitamins}

Most of the deficiencies noted with water-soluble vitamins are due to inadequate oral intake, often related to etiology of cirrhosis (particularly alcoholic cirrhosis) (25). In addition to poor intake, several vitamins have additional mechanisms by which they become depleted. Folate and vitamin B12, which is stored in the liver, may become rapidly depleted with advancing liver disease (25). In some cases, vitamin B12 levels may even be elevated because of a failure of hepatic uptake and extravasation of stored cobalamin into circulation (25).

\section{Zinc}

Zinc serves a multitude of functions of the body; it is an enzyme catalyst, structural stabilizer, receptor modulator, antioxidant, and signaling molecule (28). The liver is the main effector of zinc homeostasis $(28,29)$. Metallothionein is a hepatically synthesized intracellular protein essential to zinc absorption; additionally, most of the body's zinc is transported in serum by albumin $(28,30)$. Absorbed zinc is initially delivered to the liver before it is distributed to other tissues, specifically muscle and bone, where a majority of it is stored $(28,30)$. In the setting of cirrhosis and decreased protein synthetic capability, zinc absorption and transport throughout the body is markedly compromised $(29,30)$. Metallothionein synthesis is also directly correlated to serum zinc levels; decreased oral intake of zinc-rich foods is a significant cause of deficiency and is associated with decreased absorption and distribution (28-30). Lastly, increased muscle degradation commonly observed in cirrhosis can deplete zinc stores and lead to wasting (28). Zinc wasting is of significant consequence in the urea cycle, where it serves as an enzyme cofactor; deficiency impairs the conversion of ammonia to urea, which contributes to hepatic encephalopathy (HE) (see Figure 1 below) (31). 


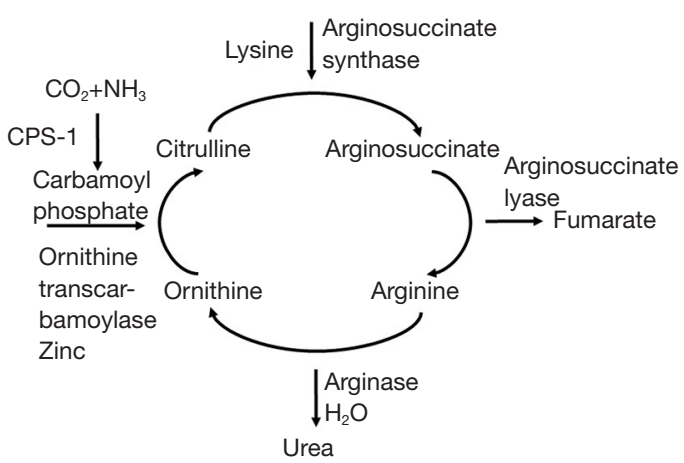

Figure 1 The urea cycle. Zinc is a cofactor of the enzyme ornithine transcarbamoylase. With zinc deficiency in cirrhosis, activity of ornithine transcarbamoylase is decreased, which causes a reduction of ammonia metabolism to urea. CPS-1, carbamoyl phosphate synthetase I; NH3, ammonia.

\section{Macro- and micronutrient abnormalities and their clinical implications in cirrhosis}

\section{Sarcopenia}

Abnormalities of protein metabolism, specifically increased catabolism in relation to anabolism, result in sarcopenia, or muscle mass depletion $(2,3,5,6,32)$. Sarcopenia is a common complication of cirrhosis, with a mean occurrence of $48 \%$ (ascertained from a metanalysis of 20 studies involving 4,037 patients); other literature dictates a prevalence range of $40-70 \%(32,33)$. Additionally, men were more likely to be sarcopenic than women $(61.6 \%$ and $36 \%$, respectively) (33). Sarcopenia is closely related to frailty, a state of physical vulnerability and weakness that predisposes one to medical complications, clinical decline and mortality (34). In many different studies, the presence of sarcopenia generally portends an elevation in the risk and occurrence adverse outcomes including increased infection rates, and decreased length of survival after transplantation, and overall mortality $(33,35)$.

\section{Bone abnormalities}

Abnormal vitamin D metabolism can increase the risk of bone disease in cirrhotic patients. The mechanism involves a combination of diminished calcium absorption from the gut, decreased osteoblast activity causing decreased bone formation, and potentially increased osteoclast-mediated bone resorption $(36,37)$. Secondary hyperparathyroidism may also be a factor, though some studies demonstrate that
PTH levels may not correlate with bone disease (36-38). Low vitamin D levels (defined as levels below $10 \mathrm{ng} / \mathrm{mL}$ ) were more likely to be found in patients with more severe liver disease; a vitamin $\mathrm{D}$ level below the $10 \mathrm{ng} / \mathrm{mL}$ threshold was determined to be a strong predictor of mortality (39). A significant number of patients suffer from bone disease with studies demonstrating range estimates of $17-68 \%$ (36). Of note, bone disease impacts trabecular bone (i.e., the lumbar spine) more significantly than cortical bone (i.e., femur neck) because of relatively increased turnover in the trabecular bone (38). Bone disease, like sarcopenia, is closely associated with frailty; it also places cirrhotic patients at increased risk for fractures, specifically vertebral fractures, and associated complications such as increased hospital length of stay and 30-day mortality $(38,40,41)$. The risk of post-fracture adverse events was significantly elevated if patients had other clinical complications of cirrhosis, such as ascites (41).

\section{$H E$}

$\mathrm{HE}$ is one of the most severe complications of cirrhosis. It is defined as a decline in brain function in the context of liver disease (42). HE is a spectrum of neurocognitive disorders; it is classified according to etiology of disease (whether it is Type A due to acute liver failure, Type B due portosystemic shunting, or Type $\mathrm{C}$ due to cirrhosis), timeframe of symptoms (episodic, recurrent or persistent), the presence/ absence of precipitating factors, and, most commonly, the severity of symptoms (see Table 1 below) $(42,43)$.

The prevalence of $\mathrm{HE}$ varies depending on the type. Overt HE (OHE) is estimated to be approximately between $10-70 \%$ across all cirrhotic patients; the prevalence increases in decompensated cirrhosis (approximately $20 \%$ ) and much more so in patients who have received transjugular intrahepatic portosystemic shunt (TIPS) $(10-50 \%)(28,44)$. Covert HE in noted to occur in $20-80 \%$ of patients (44). HE due to cirrhosis (Type C) has many different inciting factors that creates an accumulation of toxic material, usually ammonia, that cannot be cleared by the liver due to its diminished capacity for conversion to urea (43). Nutritional derangements that can precipitate HE include hyponatremia, hypokalemia, hypomagnesemia, hypozincemia, and sarcopenia (see Table 2) (42).

\section{Hyponatremia}

Hyponatremia is a risk factor for precipitation of hepatic 
Table 1 West-Haven criteria for classification of HE symptoms

\begin{tabular}{|c|c|}
\hline Grade & Signs and symptoms \\
\hline Unimpaired & No apparent encephalopathy \\
\hline Minimal & $\begin{array}{l}\text { Grossly normal mental status. Assessment of } \\
\text { psychomotor or cognitive function demonstrating } \\
\text { abnormal results }\end{array}$ \\
\hline \multirow[t]{5}{*}{ Grade I } & Absence of awareness \\
\hline & Hyperexcitability (elevated mood or anxiety) \\
\hline & Attention deficits \\
\hline & Decreased capacity for basic arithmetic \\
\hline & Alteration in sleep pattern/behavior \\
\hline \multirow[t]{6}{*}{ Grade II } & Lack of energy/apathy \\
\hline & Disorientation for time \\
\hline & Change in disposition/personality \\
\hline & Unsuitable behaviors \\
\hline & Coordination issues/dyspraxia \\
\hline & Asterixis \\
\hline \multirow[t]{3}{*}{ Grade III } & $\begin{array}{l}\text { Altered mentation ranging from gross confusion to } \\
\text { somnolence }\end{array}$ \\
\hline & Variable arousable to external stimulation \\
\hline & Abnormal behaviors \\
\hline Grade IV & Unresponsiveness/coma \\
\hline
\end{tabular}

Table 2 Nutrient derangement and implication in cirrhosis

\begin{tabular}{|c|c|c|}
\hline Nutrient & $\begin{array}{l}\text { Physiological } \\
\text { change }\end{array}$ & Complication \\
\hline \multirow[t]{2}{*}{$\begin{array}{l}\text { Protein } \\
\text { dysmetabolism }\end{array}$} & \multicolumn{2}{|c|}{$\begin{array}{l}\text { Decreased muscle synthesis, Sarcopenia } \\
\text { increased muscle catabolism } \\
\text { for gluconeogenesis }\end{array}$} \\
\hline & $\begin{array}{l}\text { Diminished muscle } \\
\text { metabolism of ammonia }\end{array}$ & $\begin{array}{l}\text { Hepatic } \\
\text { encephalopathy }\end{array}$ \\
\hline Hyponatremia & Cerebral swelling & $\begin{array}{l}\text { Hepatic } \\
\text { encephalopathy }\end{array}$ \\
\hline $\begin{array}{l}\text { Hypokalemia and } \\
\text { hypomagnesemia }\end{array}$ & $\begin{array}{l}\text { Increased ammonia } \\
\text { production in kidney }\end{array}$ & $\begin{array}{l}\text { Hepatic } \\
\text { encephalopathy }\end{array}$ \\
\hline Hypozincemia & $\begin{array}{l}\text { Decreased hepatic } \\
\text { conversion of ammonia to } \\
\text { urea, glutamine synthesis }\end{array}$ & $\begin{array}{l}\text { Hepatic } \\
\text { encephalopathy }\end{array}$ \\
\hline $\begin{array}{l}\text { Vitamin D } \\
\text { deficiency }\end{array}$ & $\begin{array}{l}\text { Decreased calcium } \\
\text { absorption, incorporation } \\
\text { into bone }\end{array}$ & $\begin{array}{l}\text { Bone } \\
\text { disease }\end{array}$ \\
\hline
\end{tabular}

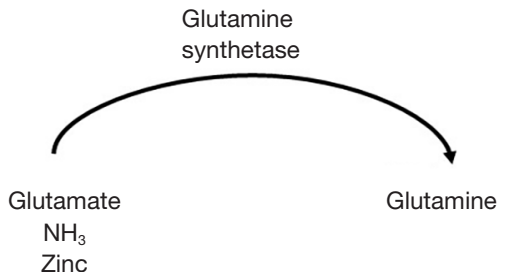

Figure 2 Glutamine synthesis catalyzed by glutamine synthetase. Zinc is a cofactor in the reaction catalyzed by the enzyme glutamine synthetase. Decreased zinc levels in cirrhosis reduce the conversion of glutamate and ammonia to glutamine. $\mathrm{NH}_{3}$, ammonia.

encephalopathy. Ammonia uptake into the astrocytes promotes generation of glutamine; increased intracellular concentrations of solute promotes cerebral swelling via increased free water shifts into cells (12). Astrocyte swelling leads to disruption of cellular processes that produce the symptoms of HE. Hyponatremia may exacerbate this swelling due to a further increased driving force of free water from the relatively hypo-osmolar plasma into the relatively hyper-osmolar cell (45).

\section{Hypokalemia and hypomagnesemia}

Hypokalemia promotes ammonia production in the proximal tubule by stimulating glutamine uptake and deamination (46). Hypomagnesemia is a direct risk factor for hypokalemia. Magnesium ions block the renal outer medullary potassium (ROMK) channel, preventing potassium efflux; decreased magnesium ions promote potassium leaking and wasting, leading to hypokalemia (47).

\section{Hypozincemia}

Zinc is a direct and essential cofactor in ammonia metabolism, specifically the urea cycle and muscle glutamine synthetase; deficiencies of zinc cause accumulation of ammonia due to decreased urea cycle activity and glutamine production (see Figures 1,2 above) (28,48-50).

\section{Sarcopenia}

In the absence of the urea cycle, nitrogen metabolism is 


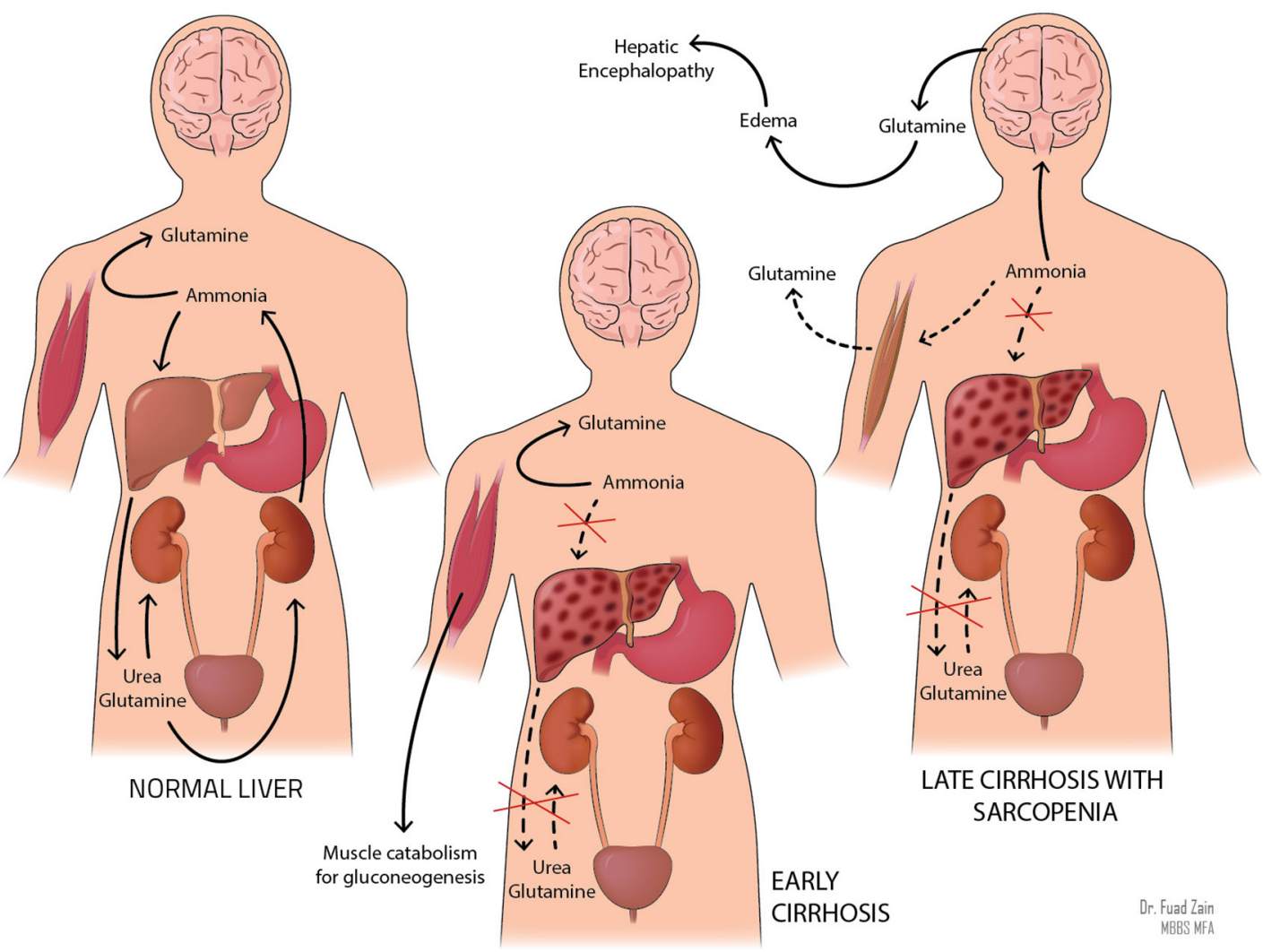

Figure 3 Mechanism by which cirrhosis and cirrhosis-related sarcopenia contributes to ammonia accumulation and HE. Solid lines delineate highly active pathways; dashed lines indicate pathways of comparatively diminished activity. In a normally functioning liver (left), ammonia is converted to urea in the liver and glutamine in the liver and the muscle. In early cirrhosis (middle), the liver's ability to regulate ammonia levels through glutamine synthesis is diminished; metabolism is shunted to the muscle. In advanced cirrhosis (right), sarcopenia reduces the volume of muscle available to consume ammonia; ammonia is directed to the brain, where increased glutamine synthesis (and resultant intracellular fluid shifts) can precipitate HE. HE, hepatic encephalopathy.

shifted to the muscle, where muscular glutamine synthetase consumes ammonia and generates glutamine to be excreted by the kidneys (51). In the setting of sarcopenia-defining muscle wasting and depletion of glutamine synthetase, ammonia accumulation and shunting to the brain can precipitate HE (see Figure 3 above) (51).

\section{Hyperkalemia}

Hyperkalemia can be considered an indicator of prognosis and mortality because of its correlation with kidney injury and failure (52). The odds of mortality in a 90-day period was determined to be 11 times higher in cirrhotic patients who had kidney injury compared to patients without kidney injury (53). Cirrhotic patients with hyperkalemia and without hyperkalemia had 90 -day mortality rates of $44.4 \%$ and $24.7 \%$ respectively; patients with kidney injury and hyperkalemia had a 90 -day mortality death rate of $80.3 \%$, compared to $56.6 \%$ in patients with kidney injury without hyperkalemia (53).

\section{Nutritional intervention in cirrhotic patients}

Identification of the mechanisms of nutrient derangements and their potentially life-threatening complications creates an urgency to incorporate nutritional consideration into the evaluation of the cirrhotic patient. In addition to medical management, a targeted and aggressive nutrition-conscious 
plan should be outlined based on each patient's needs. The following is a proposed comprehensive approach to the care of the cirrhotic patient.

\section{Establish a patient profile}

On initial diagnosis with cirrhosis, patients should undergo a complete baseline body profile. Components of this body profile should include height, weight, body mass index (BMI), body fat and muscle composition, bone density, degree of frailty, and assessment of presence (and if present, severity) of HE. Having such a baseline would provide a general idea of degree of sarcopenia, presence of bone disease, assessment of presence and risk of fracture, and baseline neurological functioning. BMI can be assessed by regular height and weight measurements. Body composition would ideally be assessed via dual-energy X-ray absorptiometry (DEXA) for several reasons. For one, DEXA provides a highly reliable estimation of muscle mass with minimal radiation exposure (54,55); additionally, DEXA is a cost-effective option as it would provide information regarding muscle mass and bone integrity simultaneously. Assessment of frailty can be performed via different validated tests such as the Clinical Frailty Scale, FRAIL (fatigue, resistance, ambulation, illness, and loss of weight) Scale, and the Timed Get-Up-and-Go Test or testing of qualities such as grip strength, gait speed, chair stands, and ability to perform activities of daily living $(56,57)$. Assessment of HE can be implemented by assessment tools such the West-Haven score and the FOUR Score test, which evaluates eyes, motor response, respiration, and brainstem response $(42,43,58)$. Once this baseline profile it acquired, it should be repeated at discrete intervals based on the patient's condition and interventions to assess for improvement in clinical status. Patients with cirrhosis should also undergo characterization per the Model for End-Stage Liver Disease (MELD) Score (which assesses the severity of liver disease) and the Child-Pugh score (which assesses the prognosis of chronic liver disease, specifically cirrhosis).

\section{Obtain baseline laboratories/electrolyte and vitamin repletion}

Monitoring of electrolytes is one of the most important ways to assess for metabolic deficiencies. Labs such as the complete blood count (CBC) and comprehensive metabolic profile (CMP) provides invaluable information about the internal milieu, particularly regarding electrolytes. This information will direct medical management to treat correctable electrolyte derangements. Assessment of attainable vitamin and mineral levels such as folate, B12, vitamin D, iron will provide insight as to which vitamins may require supplementation. Other minerals that are not reliable assessed via serum studies would ideally be supplemented in the diet, especially if they are demonstrated to provide benefit in cirrhosis; close clinical monitoring after repletion should occur to observe for resolution of symptoms of deficiency (59).

Vitamin repletion is essential to alter the course of the disease and improve outcomes. For example, zinc supplementation was noted to reduce the impact of $\mathrm{HE}$ (specifically owed to its facilitation of the urea cycle) and the incidence of hepatocellular carcinoma (31). Vitamin D supplementation can help to increase the survival odds of cirrhotic patients and augment the immune response in cases of spontaneous bacterial peritonitis (60). Magnesium repletion has been demonstrated to slow disease progression, exert hepatoprotective qualities, and even limit hepatitis $\mathrm{C}$ virus (HCV) replication (15).

\section{Arrange for a nutritional assessment}

The information collected above is vital for establishing the needs of the patient based on their physical and metabolic profile. Given this information, it is advised that patients undergo a nutrition assessment by a nutritionist; this evaluation would determine the degree of malnutrition present, current dietary habits, and access to tools to help modify habits (61). Evaluation is essential as it can provide valuable information regarding proper practices to optimize health. An example of this is recommended protein consumption. Protein restriction was one of the recommended tenets of cirrhosis management because it was believed to contribute to minimalization of risk of hepatic encephalopathy by reducing the ammonia generated from amino acid metabolism; however, protein restriction was found to contribute to enhance muscle catabolism and increase the risk of sarcopenia (62). Now, patients are recommended to avoid protein restriction and consume approximately $1.2-1.5 \mathrm{~g} / \mathrm{kg}$ of protein per day, preferentially proteins from dairy and vegetable sources and proteins with a significant proportion of branched-chained amino acids (BCAAs) that promote protein synthesis $(61,62)$. Adequate protein consumption is essential for preventing sarcopenia 
and lowering risk for HE.

\section{Provide a palatable diet}

Poor oral intake is one of the most common risk factors for nutritional deficiency of multiple vitamins and minerals. One if the main factors that renders food unpalatable is the sodium restriction. Sodium restriction is important in reducing fluid retention that could contribute to exacerbation of ascites. However, excessive salt restriction is also counterproductive in that it may temper appetite and discourage adequate oral intake (63). Studies show that patients who had more liberal salt intake experienced more favorable outcomes, including greater albumin levels, shorter length of hospital stay, and decreased frequency of large volume paracentesis (63). Nonetheless, the diets of cirrhotic patients should strive for the minimal amount of salt required to make meals edible without increasing the risk of ascites.

\section{Maintain a bealthy weight}

Obesity is a strong influence on the genesis and subsequent worsening of chronic liver disease. The proinflammatory state generated by chemical products of excess adipose tissue promotes pathological events such as intrahepatic fat deposition and fibrosis (64). This not only initiates liver disease, but also increases risk of progression and further complications, including portal hypertension, thrombosis, progression to decompensated cirrhosis, and post-operative complications after liver transplantation (64). In fact, the incidence of decompensated cirrhosis has a positive correlation with weight (64). Therefore, safe weight reduction ideally produces benefits for cirrhotic patients, such as slowed progression to decompensated cirrhosis, better prognosis after transplantation, or avoidance of need for transplantation altogether (65). Attaining and maintaining a healthy weight can be achieved by lifestyle changes and exercise, which can result in decrease portal pressures, increased muscle mass, lower levels of fatigue, and improvement in quality of life (65-68). However, exercise recommendation requires intense screening on a per-patient basis in order to reduce complications, such as bleeding in a severely thrombocytopenic patient due to trauma (68). Other interventions, such as weightloss medications (orlistat, combination of phentermine/ topiramate) and surgery, can also provide means to weight loss. However, more information is needed to understand the benefits of those medications in this patient population; regarding surgery, patients must be thoroughly vetted and optimized to prevent exposure to post-surgical complications (65).

\section{Promote health habits}

Alcohol is one of the most important causes of liver disease. It creates derangements in lipid metabolism, including increased hepatic lipid production and storage as well as decreased transport out of the liver, both of which promotes steatosis (69). It is also directly cytotoxic; alcohol metabolism generates reactive oxygen species that induce cell damage and inflammation (69). Usually, antioxidants in the form of vitamins and minerals can counteract this insult. Chronic and excessive exposure to alcohol, in combination with poor oral intake of nutrients, can deplete antioxidants and facilitate a cycle of liver damage that can lead to cirrhosis (25). Elimination of alcohol consumption, therefore, is critical not only in preventing the progression of liver disease by removal of cytotoxic and inflammatory effects, but also preventing the aforementioned vitamin and mineral deficiencies that can precipitate complications of cirrhosis. Alcohol abuse is a complex disease that requires a multifaceted approach, consisting of psychological and pharmacological interventions, as well as the full cooperation of the patient, to achieve abstinence (69).

\section{Conclusions}

Liver dysfunction as a result of cirrhosis can create nutritional abnormalities that significantly increase the risk of mortality in patients. Therefore, in additional to medical management, cirrhotic patients require close nutritional management as well to correct metabolic derangements and optimize health outcomes.

\section{Acknowledgments}

Funding: None.

\section{Footnote}

Reporting Checklist: The authors have completed the Narrative Review reporting checklist. Available at https:// tgh.amegroups.com/article/view/10.21037/tgh-20-325/rc

Conflicts of Interest: All authors have completed the ICMJE 
uniform disclosure form (available at https://tgh.amegroups. com/article/view/10.21037/tgh-20-325/coif). Dr. SKS serves as the Editor-in-Chief of Translational Gastroenterology and Hepatology from November 2019 to October 2024. The other authors have no conflicts of interest to declare.

Ethical Statement: The authors are accountable for all aspects of the work in ensuring that questions related to the accuracy or integrity of any part of the work are appropriately investigated and resolved.

Open Access Statement: This is an Open Access article distributed in accordance with the Creative Commons Attribution-NonCommercial-NoDerivs 4.0 International License (CC BY-NC-ND 4.0), which permits the noncommercial replication and distribution of the article with the strict proviso that no changes or edits are made and the original work is properly cited (including links to both the formal publication through the relevant DOI and the license). See: https://creativecommons.org/licenses/by-nc-nd/4.0/.

\section{References}

1. Eghtesad S, Poustchi H, Malekzadeh R. Malnutrition in liver cirrhosis: the influence of protein and sodium. Middle East J Dig Dis 2013;5:65-75.

2. Iiames J, Logomarsino J. Protein recommendations for older adults with cirrhosis: a review. J Gastroenterol Hepatol Res 2014;4:1546-56.

3. Marchesini G, Bianchi G, Lucidi P, et al. Plasma ghrelin concentrations, food intake, and anorexia in liver failure. J Clin Endocrinol Metab 2004;89:2136-41.

4. Anastácio LR, Ferreira LG, Ribeiro Hde S, et al. Weight loss during cirrhosis is related to the etiology of liver disease. Arq Gastroenterol 2012;49:195-8.

5. Calmet F, Martin P, Pearlman M. Nutrition in patients with cirrhosis. Gastroenterol Hepatol (N Y) 2019; 15:248-54.

6. Tessari P. Protein metabolism in liver cirrhosis: from albumin to muscle myofibrils. Curr Opin Clin Nutr Metab Care 2003;6:79-85.

7. Kashani A, Landaverde C, Medici V, et al. Fluid retention in cirrhosis: pathophysiology and management. QJM 2008;101:71-85.

8. Schuppan D, Afdhal N. Liver cirrhosis. Lancet 2008;371:838-51.

9. Sauerbruch T, Schierwagen R, Trebicka J. Managing portal hypertensin in patients with liver cirrhosis. F1000Res
2018;7:533.

10. Moore CM, Van Thiel DH. Cirrhotic ascites review: Pathophysiology, diagnosis and management. World J Hepatol 2013;5:251-63.

11. Chung C, Iwakairi Y. The lymphatic vascular system in liver diseases: its role in ascites formation. Clin Mol Hepatol 2013;19:99-104.

12. John S, Thuluvath P. Hyponatremia in cirrhosis: pathophysiology and management. World J Gastroenterol 2015;21:3197-205.

13. Attar B. Approach to hyponatremia in cirrhosis. Clin Liver Dis (Hoboken) 2019;13:98-101.

14. Swaminathan R. Magnesium metabolism and its disorders. Clin Biochem Rev 2003;24:47-66.

15. Liu M, Yang H, Mao Y. Magnesium and liver disease. Ann Transl Med 2019;7:578.

16. Jiménez JV, Carrillo-Pérez DL, Rosado-Canto R, et al. Electrolyte and acid-base disturbances in end-stage liver disease: a physiopathological approach. Dig Dis Sci 2017;62:1855-71.

17. Moratinos J, Reverte M. Effects of catecholamines on plasma potassium the role of alpha-and betaadrenoceptors. Fundam Clin Pharmacol 1993;7:143-53.

18. Bubien JK. Epithelial $\mathrm{Na}+$ channel $(\mathrm{ENaC})$, hormones, and hypertension. J Biol Chem 2010;285:23527-31.

19. Ng CK, Chan MH, Tai MH, et al. Hepatorenal syndrome. Clin Biochem Rev 2007;28:11-7.

20. Francoz C, Durand F, Kahn J.A, et al. Hepatorenal syndrome. Clin J Am Soc Nephrol 2019;14:774-81.

21. Viera AJ, Wouk N. Potassium Disorders: Hypokalemia and Hyperkalemia. Am Fam Physician 2015;92:487-95.

22. Hunter RW, Bailey MA. Hyperkalemia: pathophysiology, risk factors and consequences. Nephrol Dial Transplant 2019;34:iii2-11.

23. Schmidt DR, Holmstrom SR, Fon Tacer K, et al. Regulation of bile acid synthesis by fat-soluble vitamins A and D. J Biol Chem 2010;285:14486-94.

24. Liu N, Feng J, Lv Y, et al. Role of bile acids in the diagnosis and progression of liver cirrhosis: a prospective observational study. Exp Ther Med 2019;18:4058-66.

25. Kozeniecki M, Ludke R, Kerner J, et al. Micronutrients in liver disease: roles, risk factors for deficiency, and recommendations for supplementation. Nutr Clin Pract 2020;35:50-62.

26. Bikle DD. Vitamin D metabolism, mechanism of action, and clinical applications. Chem Biol 2014;21:319-29.

27. Konstantakis C, Tselekouni P, Kalafeteli M, et al. 
Vitamin D deficiency in patients with liver cirrhosis. Ann Gastroenterol 2016;29:297-306.

28. Grüngreiff K, Reinhold D, Wedemeyer $\mathrm{H}$. The role of zinc in liver cirrhosis. Ann Hepatol 2016;15:7-16.

29. Himoto T, Masaki T. Associations between zinc deficiency and metabolic abnormalities in patients with chronic liver disease. Nutrients 2018;10:88.

30. Roohani N, Hurrell R, Kelishadi R, et al. Zinc and its importance for human health: an integrative review. J Res Med Sci 2013;18:144-57.

31. Hosui A, Kimura E, Tanimoto T, et al. Long-term zinc supplementation improves liver function and the risk of developing hepatocellular carcinoma. Nutrients 2018;10:1955.

32. Ebadi M, Bhanji R, Mazurak V, et al. Sarcopenia in cirrhosis: from pathogenesis to interventions. J Gastroenterol 2019;54:845-59.

33. Kim G, Kang S, Kim M, et al. Prognostic value of sarcopenia in patients with liver cirrhosis: a systematic review and metanalysis. PLOS One 2017;12:e0186990.

34. Chen HW, Dunn MA. Arresting frailty and sarcopenia in cirrhosis: future prospects. Clin Liver Dis (Hoboken) 2018;11:52-7.

35. Dasarathy S, Merli M. Sarcopenia from mechanism to diagnosis and treatment in lever disease. J Hepatol 2016;65:1232-44.

36. Patel N, Munoz S. Bone disease in cirrhosis. Clin Liver Dis (Hoboken) 2015;6:96-9.

37. Handzlik-Orlik G, Holecki M, Wilczynski K, et al. Osteoporosis in liver disease: pathogenesis and management. Ther Adv Endocrinol Metab 2016;7:128-35.

38. Turkeli M, Dursun H, Albayrak F, et al. Effects of cirrhosis on bone mineral density and bone metabolism. Eurasian J Med 2008;40:18-24.

39. Paternostro R, Wagner D, Reiberger T, et al. Low 25-OH-vitamin D levels reflect hepatic dysfunction and are associated with mortality in patients with liver cirrhosis. Wien Klin Wochenschr 2017;129:8-15.

40. Saeki C, Kanai T, Nakano M, et al. Relationship between osteosarcopenia and frailty in patients with chronic liver disease. J Clin Med 2020;9:2831.

41. Chen TL, Lin CS, Shih CC, et al. Risk and adverse outcomes of fractures in patients with liver cirrhosis: two nationwide retrospective cohort studies. BMJ Open 2017;7:e17342.

42. Ferenci P. Hepatic encephalopathy. Gastroenterol Rep (Oxf) 2017;5:138-47.

43. Ellul MA, Gholkar SA, Cross TJ. Hepatic encephalopathy due to liver cirrhosis. BMJ 2015;351:h4187.

44. Vilstrup H, Amodio P, Bajaj J, et al. Hepatic encephalopathy in chronic liver disease: 2014 practice guideline by the American Association for the Study of Liver Diseases and the European Association for the Study of the Liver. Hepatology 2014;60:715-35.

45. Giuliani C, Peri A. Effect of hyponatremia on the brain. J Clin Med 2014;3:1163-77.

46. Han K. Mechanisms of the effects of acidosis and hypokalemia on renal ammonia metabolism. Electrolyte Blood Press 2011;9:45-9.

47. Huang CL, Kuo E. Mechanism of hypokalemia in magnesium deficiency. J Am Soc Nephrol 2007;18:2649-52.

48. Mohammad MK, Zhou Z, Cave M, et al. Zinc and liver disease. Nutr Clin Pract 2012;27:8-20. Erratum in: Nutr Clin Pract 2012;27:305.

49. De Chiara F, Heebol S, Marrone G, et al. Urea cycle dysregulation in non-alcoholic fatty luver disease. J Hepatol 2018;69:905-15.

50. Cooper AJL. The role of glutamine synthetase and glutamine dehydrogenase in cerebral ammonia homeostasis. Neurochem Res 2012;37:2439-55.

51. Wijarnpreecha K, Werlang $M$, Panjawatanan $P$, et al. Association between sarcopenia and hepatic encephalopathy: a systematic review and meta-analysis. Ann Hepatol 2020;19:245-50.

52. Wallerstedt S, Simren M, Wahlin S, et al. Moderate hyperkalemia in hospitalized patients with cirrhotic ascites indicates a poor prognosis. Scand J Gastroenterol 2013;48:358-65.

53. Cai JJ, Wang K, Jiang HQ, et al. Characteristics, risk factors, and adverse outcomes of hyperkalemia in acute-on-chronic liver failure patients. Biomed Res Int 2019;2019:6025726.

54. Scafoglieri A, Clarys J. Dual energy X-ray absorptiometry: gold standard for muscle mass? J Cachexia Sarcopenia Muscle 2018;9:786-7.

55. Shepherd JA, Ng BK, Sommer MJ, et al. Body composition by DXA. Bone 2017;104:101-5.

56. Walston J, Buta B, Xue Q. Frailty screening and interventions: considerations for clinical practice. Clin Geriatr Med 2018;34:25-38.

57. Van Jacobs AC. Frailty Assessment in Patients with Liver Cirrhosis. Clin Liver Dis (Hoboken) 2019;14:121-5.

58. Mouri S, Tripon S, Rudler M, et al. FOUR score, a reliable score for assessing overt hepatic encephalopathy in cirrhotic patients. Neurocrit Care 2015;22:251-7.

59. Koop AH, Mousa OY, Pham LE, et al. An argument 
for vitamin D, A, and zinc monitoring in cirrhosis. Ann Hepatol 2018;17:920-32.

60. Jha AK, Jha SK, Kumar, A, et al. Effect of replenishment of vitamin $\mathrm{D}$ on survival in decompensated liver cirrhosis: a prospective study. World J Gastrointest Pathophysiol 2017;8:133-41.

61. European Association for the Study of the Liver. EASL clinical practice guidelines on nutrition in chronic liver disease. J Hepatol 2019;70:172-93.

62. Milke García MP. Nutritional support in the treatment of chronic hepatic encephalopathy. Ann Hepatol 2011;10:S45-9.

63. Haberl J, Zollner G, Fickert P, et al. To salt or not to salt? That is the question in cirrhosis. Liver Int 2018;38:1148-59.

64. Schiavo, L, Busetto L, Cesaretti M, et al. Nutritional issues in patients with obesity and cirrhosis. World J Gastroenterol 2018;24:3330-46.

65. Kumar N, Choudhary N. Treating morbid obesity

doi: 10.21037/tgh-20-325

Cite this article as: Warner ER 2nd, Aloor FZ, Satapathy SK. A narrative review of nutritional abnormalities, complications, and optimization in the cirrhotic patient. Transl Gastroenterol Hepatol 2022;7:5. in cirrhosis: a quest of holy grail. World J Hepatol 2015;7:2819-28.

66. Zenith L, Meena N, Ramadi A, et al. Eight weeks of exercise training increases aerobic capacity and muscle mass and reduces fatigue in patients with cirrhosis. Clin Gastroenterol Hepatol 2014;12:1920-6.e2.

67. Berzigotti A, Albillos A, Villanueva C, et al. Effects of an intensive program on portal hypertension in patients with cirrhosis and obesity: the SportDiet Study. Hepatology 2017;65:1293-305.

68. Tandon P, Ismond K.P, Riess K, et al. Exercise in cirrhosis: translating evidence and experience to practice. J Hepatol 2018;69:1164-77.

69. Addolorato G, Mirijello A, Barrio P, et al. Treatment of alcohol use disorders in patients with alcoholic liver disease. J Hepatol 2016;65:618-30. 